\title{
ANALISIS KONDISI TERAS REAKTOR DAYA MAJU AP1000 PADA KECELAKAAN SMALL BREAK LOCA
}

\author{
Andi Sofrany Ekariansyah \\ Pusat Teknologi dan Keselamatan Reaktor Nuklir, Kawasan Puspiptek, Setu, Tangerang Selatan, 15310 \\ email: andi_se@batan.go.id,telp:021-7560912,fax:021-7560913 \\ Diterima editor: 15 April 2015 \\ Direvisi editor: 6 Mei 2015 \\ Disetujui untuk publikasi: 13 Mei 2015
}

\begin{abstract}
ABSTRAK
ANALISIS KONDISI TERAS REAKTOR DAYA MAJU AP1000 PADA KECELAKAAN SMALL BREAK LOCA. Kecelakaan yang diakibatkan oleh kehilangan pendingin (loss of coolant accident / LOCA) dari sistem reaktor merupakan kejadian dasar desain yang tetap diantisipasi dalam desain reaktor daya yang mengadopsi teknologi Generasi II hingga IV. LOCA ukuran kecil (small break LOCA) memiliki dampak yang lebih signifikan terhadap keselamatan dibandingkan LOCA ukuran besar (large break LOCA) seperti terlihat pada kejadian Three-Mile Island (TMI). Fokus makalah adalah pada analisis small break LOCA pada reaktor daya maju Generasi III+ yaitu AP1000 dengan mensimulasikan tiga kejadian pemicu yaitu membukanya katup Automatic Depressurization System (ADS) secara tak disengaja, putusnya salah satu pipa Direct Vessel Injection (DVI) secara double-ended, dan putusnya pipa lengan dingin dengan diameter bocoran 10 inci. Metode yang digunakan adalah simulasi kejadian pada model AP1000 yang dikembangkan secara mandiri menggunakan program perhitungan RELAP5/SCDAP/Mod3.4. Dampak yang ingin dilihat adalah kondisi teras selama terjadinya small break LOCA yang terdiri dari pembentukan mixture level dan transien temperatur kelongsong bahan bakar. Hasil simulasi menunjukkan bahwa mixture level untuk semua kejadian small break LOCA berada di atas tinggi teras aktif yang menunjukkan tidak terjadinya core uncovery. Adanya mixture level berpengaruh pada transien temperatur kelongsong yang menurun dan menunjukkan pendinginan bahan bakar yang efektif. Hasil di atas juga identik dengan hasil perhitungan program lain yaitu NOTRUMP. Keefektifan pendinginan teras juga disebabkan oleh berfungsinya injeksi pendingin melalui fitur keselamatan pasif yang menjadi ciri reaktor daya AP1000. Secara keseluruhan, hasil analisis menunjukkan model AP1000 yang telah dikembangkan dengan RELAP5 dapat digunakan untuk keperluan analisis kecelakaan dasar desain pada reaktor daya maju AP1000.
\end{abstract}

Kata kunci: analisis, mixture level, temperatur kelongsong, small break LOCA, RELAP5.

\begin{abstract}
ANALYSIS ON THE CORE CONDITION OF AP1000 ADVANCED POWER REACTOR DURING SMALL BREAK LOCA. Accident due to the loss of coolant from the reactor boundary is an anticipated design basis event in the design of power reactor adopting the Generation II up to IV technology. Small break LOCA leads to more significant impact on safety compared to the large break LOCA as shown in the Three-Mile Island (TMI). The focus of this paper is the small break LOCA analysis on the Generation III ${ }^{+}$ advanced power reactor of AP1000 by simulating three different initiating events, which are inadvertent opening of Automatic Depressurization System (ADS), double-ended break on one of Direct Vessel Injection (DVI) pipe, and 10 inch diameter split break on one of cold leg pipe. Methodology used is by simulating the events on the AP1000 model developed using RELAP5/SCDAP/Mod3.4. The impact analyzed is the core condition during the small break LOCA consisting of the mixture level occurrence and the fuel cladding temperature transient. The results show that the mixture level for all small break LOCA events are above the active core height, which indicates no core uncovery event. The development of the mixture level affect the fuel cladding temperature transient, which shows a decreasingly trend after the break, and the effectifeness of core cooling. Those results are identical with the results of other code of NOTRUMP. The resulted core cooling is also due to the function of coolant injection from passive safety feature, which is unique in the AP1000 design. In overall, the result of analysis shows that the AP1000 model developed by the RELAP5 can be used for analysis of design basis accident considered in the AP1000 advanced power reactor.
\end{abstract}

Keywords: analysis, mixture level, fuel cladding temperature, small break LOCA, RELAP5. 


\section{PENDAHULUAN}

Untuk menghindari terjadinya suatu kecelakaan yang menyebabkan terlepasnya partikel radioaktif ke lingkungan, desain PLTN harus selalu menyediakan fungsi dasar keselamatan reaktor yaitu mengendalikan daya reaktor dan mampu memadamkan reaktor bila diperlukan, mendinginkan bahan bakar di dalam teras reaktor, dan mencegah terlepasnya partikel radioaktif ke lingkungan melalui penerapan penghalang berlapis. Penyediaan fungsi dasar tersebut harus diperkuat melalui penerapan konsep pertahanan berlapis yang terdiri dari tindakan pencegahan dan mitigasi kecelakaan [1]. Untuk dapat menentukan persyaratan keselamatan pada suatu desain PLTN maka dibuat suatu kategori kondisi kecelakaan yang mendasari suatu desain PLTN sesuai dengan kriteria desain tertentu agar desain tersebut mampu menjaga kerusakan bahan bakar dan terlepasnya bahan radioaktif pada batasan yang ditentukan [2]. Kategori kecelakaan tersebut disebut sebagai kecelakaan dasar desain dimana kecelakaan kehilangan pendingin (loss of coolant accident / LOCA) termasuk di dalamnya. Potensi kejadian LOCA telah diantisipasi sejak desain awal PLTN yang disebut sebagai PLTN Generasi II [3] dan tetap dipertimbangkan hingga PLTN Generasi IV [4]. Kerentanan PLTN terhadap kejadian LOCA ditunjukkan oleh kejadian kecelakaan di PLTN Three-Mile Island (TMI) unit 2 pada Maret 1979 yang dikategorikan sebagai LOCA ukuran kecil (small break LOCA). Kejadian tersebut menjadi dasar dalam penetapan persyaratan desain sistem pendinginan teras darurat (Emergency Core Cooling System / ECCS) seperti ditetapkan oleh USNRC sebagai kriteria keselamatan bahan bakar yaitu 10 CFR 50.46 [5].

Kejadian small break LOCA juga menjadi pertimbangan keselamatan dalam desain reaktor daya maju AP1000 yang didesain oleh Westinghouse yang masuk dalam kategori reaktor daya Generasi III+. AP1000 merupakan salah satu objek yang menarik karena selain memiliki karakteristika sistem keselamatan Generasi III+ juga dalam proses konstruksi di China [6]. Berdasarkan dokumen AP1000 pada Bab 15 mengenai Accident Analyses [7], small break LOCA termasuk dalam kategori Kondisi III dari 4 kondisi kejadian, dimana secara definisi merupakan kegagalan yang jarang terjadi (infrequent faults) selama masa operasi reaktor [8]. Beberapa penelitian mengenai small break LOCA telah dilakukan secara numerik seperti simulasi aktuasi salah satu katup ADS [9] dan simulasi putusnya lengan dingin ukuran 10 inch [10], 2 inch [8,11], dan beberapa ukuran [12], selain analisis yang dilakukan oleh Westinghouse untuk keperluan lisensi AP1000.

Makalah ini difokuskan pada analisis keselamatan reaktor daya maju yaitu AP1000 akibat kejadian small break LOCA dengan menganalisis dampaknya pada bagian teras reaktor. Analisis keselamatan dilakukan dengan mensimulasikan tiga kejadian kecelakaan yang masuk dalam kategori small break LOCA yaitu aktuasi Automatic Depressurization System (ADS) secara tak disengaja, putusnya pipa Direct Vessel Injection (DVI) secara double-ended, dan putusnya pipa lengan dingin dengan diameter bocoran 10 inchi. Pada makalah ini, semua kejadian tersebut disimulasikan menggunakan program perhitungan termohidraulika RELAP5/SCDAP/Mod3.4 berdasarkan model AP1000 yang dikembangkan secara mandiri [13] untuk menunjukkan kemampuan AP1000 dalam melakukan proses depresurisasi terkendali pada sistem pendingin primer dan injeksi pendingin melalui sistem pendinginan teras darurat secara pasif. Dampak pada kondisi teras ditunjukkan pada integritas kelongsong bahan bakar dan fenomena perubahan fase pendingin di dalam teras selama proses pembuangan pendingin primer akibat kebocoran. Keunggulan makalah ini adalah pada metode pengembangan model AP1000 yang digunakan untuk simulasi small break LOCA yang sepenuhnya didasarkan pada deskripsi teknis dalam dokumen AP1000 [7] dan perbandingan tiga kejadian yang berbeda. Bila dibandingkan dengan Referensi [8], simulasi small break LOCA juga dilakukan dengan RELAP5, namun dengan menggunakan model bejana reaktor daya Surry yang dimodifikasi. Referensi $[10,11,12]$ juga melakukan pemodelan AP1000 dengan data yang lebih lengkap dan akurat mengingat sedang dibangun di China. Dengan melakukan analisis tersebut, diharapkan diperoleh pemahaman yang lebih baik mengenai keakuratan pemodelan yang telah dibuat karena keterbatasan data untuk dapat mensimulasikan kejadian kecelakaan. Keakuratan pemodelan reaktor daya AP1000 yang dikembangkan dengan RELAP5 diperlukan untuk melihat sejauh mana model tersebut dapat digunakan sebagai referensi 
yang menunjukkan tingkat keselamatan reaktor daya AP1000 sebagai bagian dari proses verifikasi keselamatan bilamana AP1000 dipilih untuk dibangun di Indonesia.

\section{POKOK BAHASAN}

\section{Fenomena Small Break LOCA pada Reaktor Daya}

Pembahasan mengenai small break LOCA dibatasi pada reaktor daya tipe pressurized water reactor (PWR) sesuai tipe reaktor daya AP1000 yang digunakan dalam analisis ini. Small break LOCA pada sistem primer didefinisikan sebagai kebocoran pendingin melalui lubang perpipaan dengan luasan bocoran sama dengan atau kurang dari $10 \%$ dari luas penampang lengan dingin atau perpipaan inlet bejana sehingga meliputi semua penetrasi pada batasan sistem primer [14]. Diameter ukuran lubang bocoran yang dipertimbangkan maksimum adalah $12 \mathrm{~cm}(4,72$ inchi) pada perpipaan sistem primer seperti ditunjukkan dalam FSAR PLTN Zion [3]. Penelitian lebih lanjut menetapkan kategori small break LOCA yaitu pada luas ukuran kebocoran kurang dari $1 \mathrm{ft}^{2}(0,09$ $\mathrm{m}^{2}$ ) [15], seperti diterapkan dalam analisis LOCA pada AP1000 yang menaikkan batas diameter lubang kebocoran (limiting break) yang dianalisis hingga10 inch $\left(0,05 \mathrm{~m}^{2}\right)$ [7] di lengan dingin.

Transien kejadian small break LOCA dapat dikarakterisasi oleh 5 periode waktu yaitu blowdown, sirkulasi alam, loop seal clearance, boil-off dan core uncovery [14], dimana setiap periode memiliki lama waktu yang berbeda bergantung pada ukuran bocoran dan sistem yang bekerja. Periode blowdown ditandai dengan depresurisasi sistem primer secara cepat, trip reaktor, trip pompa primer dan injeksi tekanan tinggi (High Pressure Injection System / HPIS). Periode sirkulasi alam ditandai dengan terbentuknya uap (void) di bagian atas tube pembangkit uap, bagian atas bejana dan upper plenum dan pembuangan kalor peluruhan teras melalui pembangkit uap secara alami. Periode loop seal clearance ditandai dengan mengalirnya uap yang tertahan di loop seal pompa primer melalui bocoran sehingga aliran bocoran berupa uap (steam) dan teras kembali tergenang (recovery) hingga ketinggian nosel lengan dingin. Pada periode boil-off (pendidihan) level campuran inventori pendingin di teras akan turun akibat proses pendidihan di dalam bejana dan dapat mencapai level terendahnya yang mengakibatkan deep core uncovery. Pada akhir periode ini biasanya tekanan sistem primer telah turun hingga aktuasi pompa injeksi tekanan rendah (Low Pressure Injection System / LPIS) atau akumulator dapat dilakukan untuk menyamai laju pendidihan pendingin teras. Periode core recovery ditunjukkan dengan tergenangnya teras oleh air pendingin darurat dan terjadi pembasahan bahan bakar oleh low quality mixture melalui proses quenching yang menandai akhir dari sekuensi small break LOCA. Contoh perbedaan sekuensi pada kejadian small break LOCA ditunjukkan pada hasil eksperimen pada fasilitas ROSA IV LSTF dengan $5 \%$ break di lengan dingin dan HPIS tidak tersedia seperti ditunjukkan pada Gambar 1 [16].

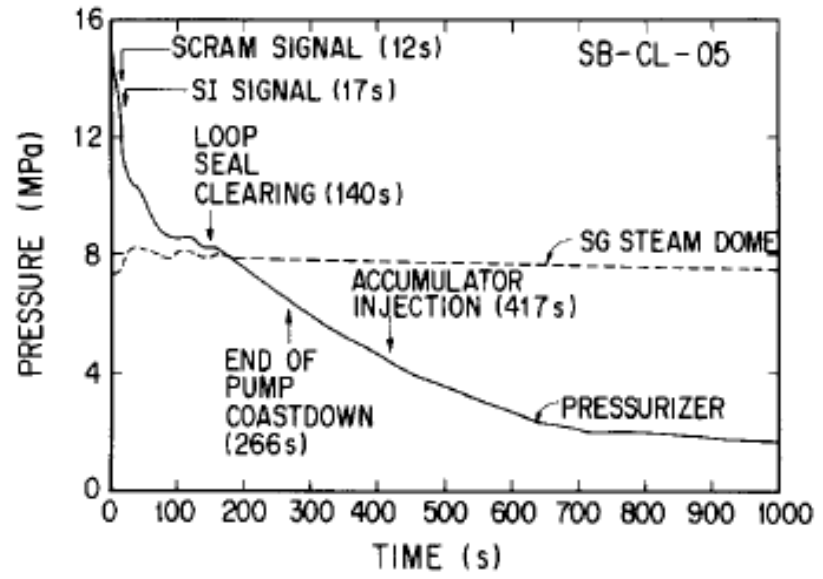

Gambar 1. Sekuensi small break LOCA pada fasilitas eksperimen ROSA IV LSTF [16] 


\section{Kriteria keselamatan terhadap kejadian small break LOCA}

Untuk mengantisipasi kejadian LOCA, keselamatan reaktor dicapai melalui fungsi ECCS, dimana US-NRC telah menetapkan peraturan mengenai persyaratan kinerja ECCS seperti diuraikan dalam 10 CFR part 50.46 yang juga disebut sebagai kriteria penerimaan untuk kejadian LOCA [5,17]. Beberapa kriteria tersebut adalah:

- Temperatur kelongsong elemen bahan bakar maksimum harus tidak melebihi $2200{ }^{\circ} \mathrm{F}$ (1470 $\mathrm{K} / 1204^{\circ} \mathrm{C}$ )

- Transien temperatur kelongsong harus dihentikan pada waktu ketika geometri teras masih dapat didinginkan

- Temperatur teras harus dikurangi dan kalor peluruhan harus dapat dibuang selama waktu yang lama mempertimbangkan adanya radioaktifitas umur panjang di teras

Berdasarkan kriteria di atas, desain ECCS pada reaktor daya harus dapat memenuhi persyaratan keselamatan di bagian teras yang ditunjukkan dengan batasan temperatur kelongsong bahan bakar maksimum. Fungsi ECCS pada Generasi II reaktor banyak bergantung pada sistem aktif seperti HPIS, LPIS, dan satu sistem pasif yaitu akumulator. Untuk mengurangi ketergantungan sistem keselamatan terhadap suplai daya listrik dan intervensi operator maka didesain sistem keselamatan yang berfungsi secara pasif seperti terlihat pada desain AP1000.

\section{Mitigasi Small Break LOCA pada AP1000}

Reaktor daya AP1000 terdiri dari dua untai pendingin dengan daya 1000 MWe yang dikembangkan oleh Westinghouse dan telah mendapat persetujuan desain akhir dari US-NRC pada tahun 2005. Untuk memitigasi small break LOCA, AP1000 dilengkapi dengan fitur keselamatan pasif yang terintegrasi dalam sistem pendinginan teras pasif. Uraian lengkap mengenai sistem pendinginan teras secara pasif dapat dilihat pada referensi [18] dan ditunjukkan pada Gambar 2. Sistem tersebut terdiri dari:

- Dua tangki makeup teras (Core Makeup Tank / CMT) bertekanan sebagai penyedia air borat ke bejana reaktor pada semua kondisi tekanan

- Dua akumulator sebagai penyedia air borat ke bejana reaktor bila tekanan sistem primer turun ke bawah nilai 4,83 MPa

- Satu tangki penyimpan air isi ulang dalam sungkup (Incontainment Refueling Water Storage Tank / IRWST) sebagai penyedia air injeksi ke bejana reaktor untuk pendinginan jangka panjang

- Penukar kalor untuk membuang kalor peluruhan secara pasif (Passive Residual Heat Removal Heat Exchanger (PRHR-HX) yang terendam dalam tangki IRWST sebagai pembuang kalor sistem primer pada semua kondisi tekanan

- Sistem depresurisasi automatis (Automatic Depressurization System / ADS) yang terdiri dari kelompok katup yang terhubung dengan pressurizer dan lengan panas sebagai fitur penurun tekanan sistem primer sehingga akumulator dapat bekerja 


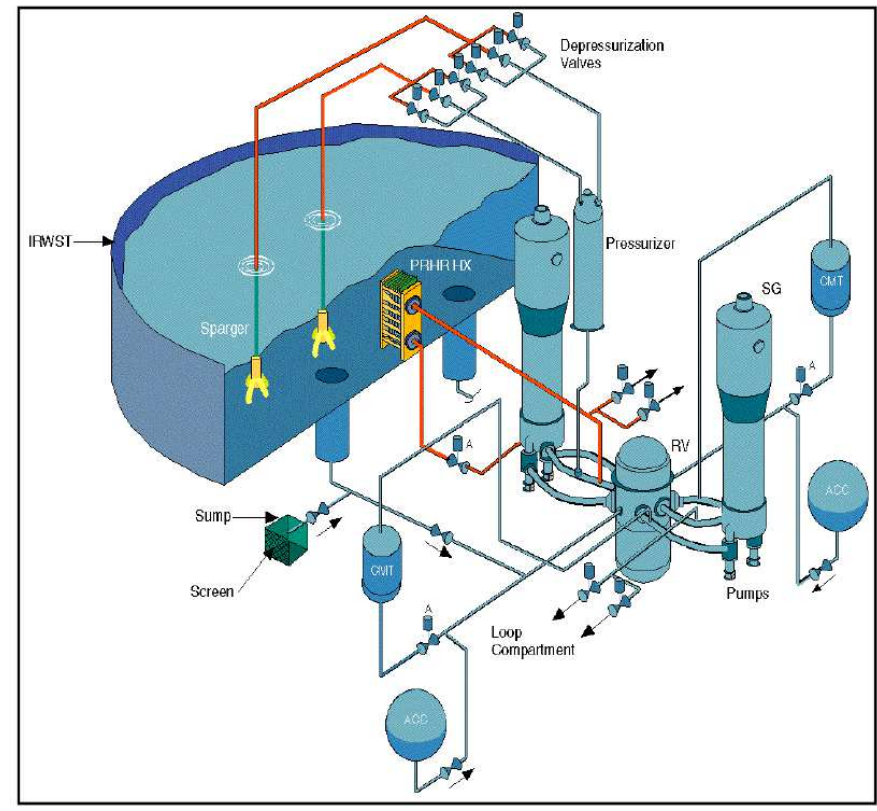

Gambar 2. Skema sistem pendinginan teras pasif pada AP1000 [19]

Pengoperasian tangki CMT dan PRHR-HX berperan dalam tahapan blowdown dan sirkulasi alam setelah small break LOCA dengan menginjeksi pendingin ke bejana reaktor melalui pipa injeksi bejana langsung (DVI) secara gravitasi dan membuang kalor peluruhan teras setelah trip reaktor. Pada kondisi sistem primer masih bertekanan dan level air di tangki CMT mulai berkurang, sistem ADS dapat bekerja untuk menurunkan tekanan hingga mencapai setting kerja akumulator untuk menginjeksi air borat melalui pipa DVI. Setelah semua air di dalam akumulator mengisi bejana reaktor dan tekanan sistem primer turun mendekati kondisi tekanan udara sungkup, air di dalam tangki IRWST mulai mengisi bejana reaktor secara gravitasi untuk mengakhiri transien small break LOCA dan memulai pendinginan teras jangka panjang. Fenomena termohidraulika di atas telah dianalisis melalui serangkaian eksperimen pada fasilitas APEX [19] dan secara simulasi numerik [10].

\section{METODOLOGI}

Kondisi teras akibat small break LOCA pada AP1000 akan dianalisis melalui simulasi numerik menggunakan RELAP5/SCDAP/Mod3.4. Untuk itu harus dibuat model AP1000 yang menggambarkan semua komponen sistem primer, sekunder dan keselamatan pasif. Pengembangan model AP1000 dilakukan secara bertahap dengan mengacu pada uraian deskripsi sistem dan komponen yang terdapat pada dokumen kontrol desain AP1000 [7]. Tahapan pengembangan model AP1000 dapat dilihat secara rinci pada beberapa referensi $[20,21,22]$. Pengujian model yang dibuat perlu dilakukan untuk mengetahui keakuratan model karena sumber referensi data hanya berupa uraian dokumen.. Salah satunya dengan melakukan simulasi kecelakaan putusnya salah satu pipa Direct Vessel Injection (DVI) dan membandingkan hasilnya dengan simulasi NOTRUMP [23]. Gambar 3 menunjukkan nodalisasi model reaktor daya AP1000 yang telah dikembangkan. 


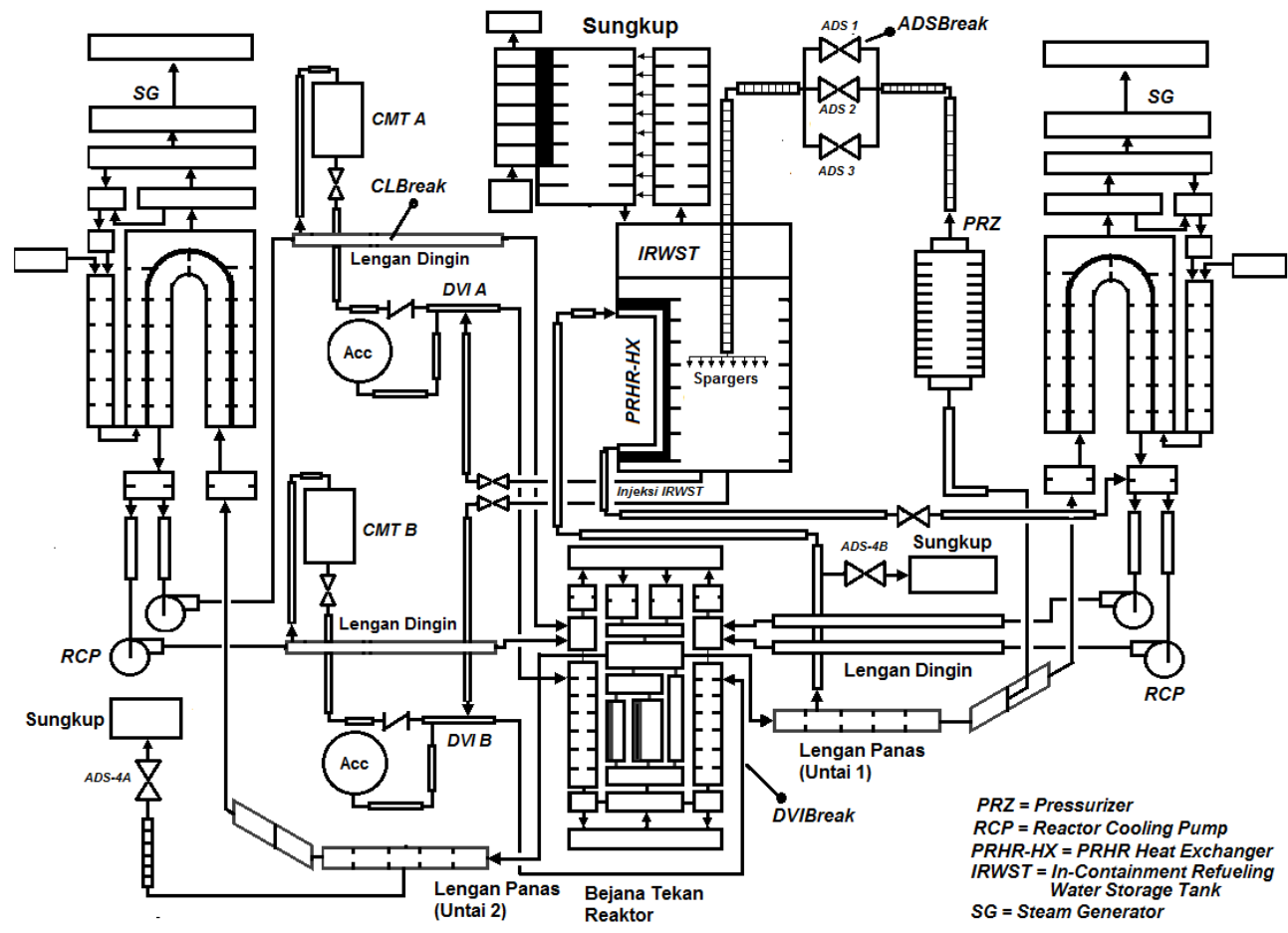

Gambar 3. Nodalisasi AP1000 menggunakan RELAP5 dan posisi small break LOCA [22]

Nodalisasi AP1000 di atas menggambarkan komponen hidrodinamik dari sistem reaktor yang memiliki sifat termohidraulika yaitu tekanan, temperatur, laju alir, dan fasa dari fluida air dan gas (condensable atau non-condensable). Teras reaktor dibagi menjadi hot channel, average channel, dan bypass channel. Hot channel adalah pendingin yang mengalir di dalam satu perangkat bahan bakar, dimana dayanya dihitung berdasarkan nilai nuclear enthapy hot channel factor 1,65 (1/60 dari daya total $3400 \mathrm{MWt}$ ) sesuai perhitungan AP1000 [7]. Sistem primer digambarkan sebagai pendingin yang mengalir di dalam lengan panas, tube pembangkit uap, lengan dingin, dan pendingin di dalam pressurizer untuk mendapatkan tekanan sistem 15,5 MPa. Aliran pendingin diperoleh melalui konveksi paksa dari model pompa RELAP5 dengan debit aliran sebesar 17886 $\mathrm{m}^{3} /$ jam sesuai desain. Sistem sekunder digambarkan sebagai pendingin di dalam sisi sekunder pembangkit uap dengan tekanan $6 \mathrm{MPa}$ dengan suplai air umpan untuk menghasilkan uap kering dengan laju alir $960 \mathrm{~kg} /$ detik. Sistem keselamatan pasif dimodelkan dengan pendingin di dalam tangki CMT, akumulator, perpipaan DVI, perpipaan PRHR dan tangki IRWST. Sistem ADS dimodelkan dengan serangkaian katup (katup ADS tingkat 1 hingga 4) yang terhubung dengan bagian atas pressurizer, perpipaan, dan outlet pipa (sparger) yang terendam di dalam tangki IRWST.

Untuk dapat mensimulasikan tiga kejadian kategori small break LOCA, nodalisasi AP1000 harus dimodifikasi dengan masukan berikut (lihat Gambar 3 untuk posisi small break LOCA):

- Membukanya katup ADS tingkat 1 dengan total luasan 0,009032 $\mathrm{m}^{2}$ untuk mensimulasikan small break LOCA tanpa kehilangan inventori pendingin primer (ADSBreak)

- Membukanya katup trip dengan luasan 0,0506707 $\mathrm{m}^{2}$ (10 inchi) untuk mensimulasikan small break LOCA dari salah satu pipa lengan dingin (cold leg) secara split yang terhubung dengan tangki CMT (CLBreak)

- Membukanya katup trip dengan luasan 0,008107 $\mathrm{m}^{2}$ untuk mensimulasikan small break LOCA di nosel bejana dari putusnya salah satu pipa DVI secara double-ended (DVIBreak)

Kecuali kejadian ADSBreak, semua aliran kebocoran diarahkan ke satu volume yang menggambarkan ruang sungkup. Setiap kejadian small break LOCA akan memicu aktuasi protection and safety monitoring system AP1000 (PMS) dengan nilai setpoint tertentu dengan waktu tunda yang berbeda seperti ditunjukkan pada Tabel 1 di bawah ini. 
Tabel 1. Nilai setpoint untuk aktuasi protection and safety monitoring system AP1000 [7]

\begin{tabular}{|c|c|c|c|c|}
\hline \multirow{2}{*}{$\begin{array}{l}\text { Aktuasi PMS } \\
\text { Trip reaktor }\end{array}$} & \multirow{2}{*}{$\begin{array}{l}\text { Nilai setpoint } \\
\text { Tekanan reaktor } 12,41 \\
\mathrm{MPa}\end{array}$} & \multicolumn{3}{|c|}{ Kategori Small break LOCA } \\
\hline & & ADSBreak & CLBreak & DVIBreak \\
\hline Sinyal Safeguard "S" & $\begin{array}{l}\text { Tekanan reaktor } 11,72 \\
\mathrm{MPa}\end{array}$ & ADSBreak & CLBreak & DVIBreak \\
\hline Isolasi jalur uap & Setelah trip reaktor & ADSBreak & CLBreak & DVIBreak \\
\hline Isolasi jalur air umpan & Setelah sinyal "S" & ADSBreak & CLBreak & DVIBreak \\
\hline Trip pompa primer & Setelah sinyal "S" & ADSBreak & CLBreak & DVIBreak \\
\hline Katup isolasi PRHR membuka & Setelah sinyal "S" & ADSBreak & CLBreak & DVIBreak \\
\hline Katup isolasi CMT membuka & Setelah sinyal "S" & ADSBreak & CLBreak & DVIBreak \\
\hline $\begin{array}{l}\text { Katup isolasi akumulator } \\
\text { membuka }\end{array}$ & $\begin{array}{l}\text { Tekanan reaktor } 4,83 \\
\mathrm{MPa}\end{array}$ & ADSBreak & CLBreak & DVIBreak \\
\hline $\begin{array}{l}\text { Katup ADS-1 membuka } \\
\text { (Kejadian pemicu pada } \\
\text { ADSBreak) }\end{array}$ & $\begin{array}{l}67,5 \% \text { level air tangki } \\
\text { CMT }\end{array}$ & & CLBreak & DVIBreak \\
\hline Katup ADS-2 membuka & $\begin{array}{l}70 \text { detik setelah katup } \\
\text { ADS-1 }\end{array}$ & ADSBreak & CLBreak & DVIBreak \\
\hline Katup ADS-3 membuka & $\begin{array}{l}120 \text { detik setelah katup } \\
\text { ADS-2 }\end{array}$ & ADSBreak & CLBreak & DVIBreak \\
\hline \multirow[t]{2}{*}{ Katup ADS-4A membuka } & $\begin{array}{l}120 \text { detik setelah katup } \\
\text { ADS-3 }\end{array}$ & & CLBreak & DVIBreak \\
\hline & $\begin{array}{l}20 \% \text { level air tangki } \\
\text { CMT }\end{array}$ & ADSBreak & & \\
\hline Katup ADS-4B membuka & $\begin{array}{l}60 \text { detik setelah katup } \\
\text { ADS-4A }\end{array}$ & ADSBreak & CLBreak & DVIBreak \\
\hline Katup isolasi IRWST membuka & $\begin{array}{l}120 \text { detik setelah katup } \\
\text { ADS-3 }\end{array}$ & ADSBreak & CLBreak & DVIBreak \\
\hline
\end{tabular}

Nilai temperatur kelongsong bahan bakar diperoleh dengan mengukur titik terluar dari model bahan bakar secara radial di hot channel dengan variabel yang disediakan RELAP5 (httemp). Fenomena termohidraulika lainnya selama proses pembuangan pendingin akibat kebocoran ditunjukkan melalui swell level (mixture level). Mixture level disebabkan oleh pembentukan uap di dalam campuran dua fasa karena pendidihan dan flashing selama proses small break LOCA. Persamaan untuk menghitung mixture level [17] ditunjukkan dengan persamaan (1) di bawah ini:

$$
H_{\operatorname{mix}}=\frac{H_{\text {manlamani }}}{1-\alpha_{c}}
$$

Dimana $H_{\text {collapsed }}$ adalah collapsed liquid level dan $\alpha_{c}$ adalah fraksi void teras rerata. RELAP5 menghitung $H_{\text {collapsed }}$ dengan membuat persamaan numerik untuk menjumlahkan tinggi level air di setiap segmen aksial model hidrodinamik dengan variabel fraksi air (voidf), sementara $\alpha_{c}$ dihitung dengan menghitung rerata variabel fraksi uap (voidg) di setiap segmen aksial yang ingin dihitung.

\section{HASIL DAN PEMBAHASAN}

Simulasi small break LOCA pada ketiga kejadian dilakukan terpisah setelah 1000 detik simulasi kondisi tunak dengan daya termal $102 \%$. Sekuensi small break LOCA pada AP1000 memiliki karakteristika tertentu yang dapat diihat pada transien tekanan primer dan dibagi menjadi empat fase kejadian yaitu blowdown, sirkulasi alam, ADS blowdown, dan injeksi IRWST [17] seperti ditunjukkan pada Gambar 4. 


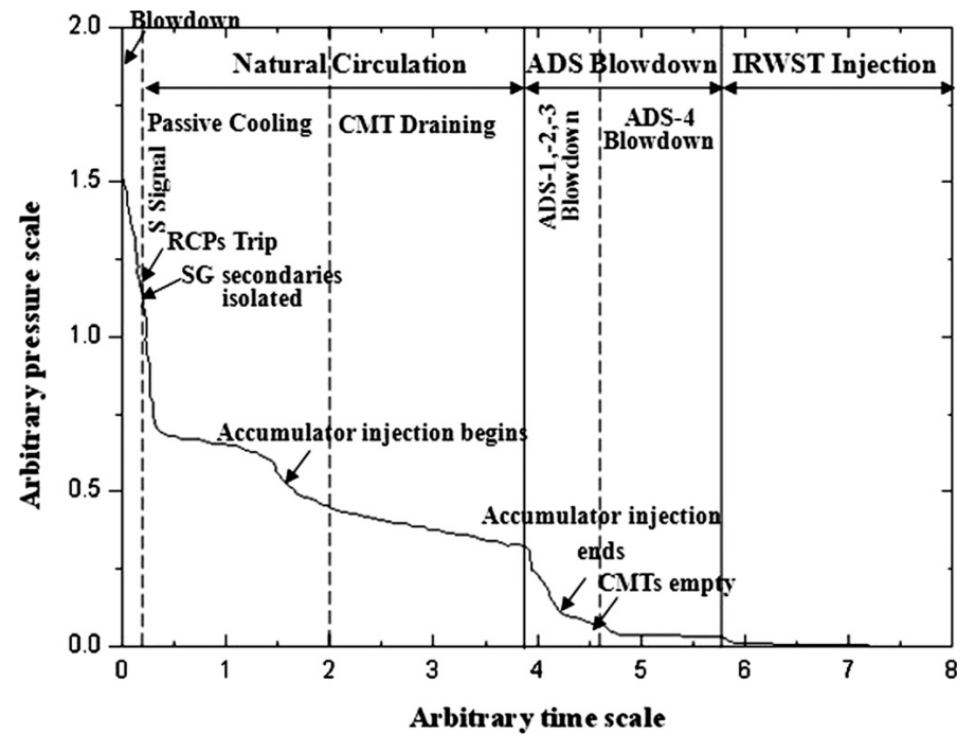

Gambar 4. Tipikal transien tekanan primer AP1000/600 pada SBLOCA [17]

Gambar 5 menunjukkan hasil simulasi small break LOCA berdasarkan model AP1000 yang telah dibuat yang menunjukkan transien tekanan primer berupa depresurisasi tekanan dari nilai operasi 154 bar untuk tiga jenis kejadian yang berbeda. Titik $\mathrm{T}=0$ detik adalah awal terjadinya kebocoran setelah 1000 detik simulasi kondisi tunak. Depresurisasi tekanan primer tersebut disebabkan oleh fase-fase kejadian small break LOCA yang dimulai dari blowdown akibat keluarnya pendingin primer, proses sirkulasi alam melalui penukar kalor PRHR-HX, aktuasi katup ADS, hingga terjadinya injeksi dari tangki IRWST. Keakuratan transien tekanan primer tersebut tidak menjadi fokus pada makalah ini walaupun dapat dibandingkan dengan hasil perhitungan NOTRUMP pada Bab 15 mengenai Accident Analyses [7].

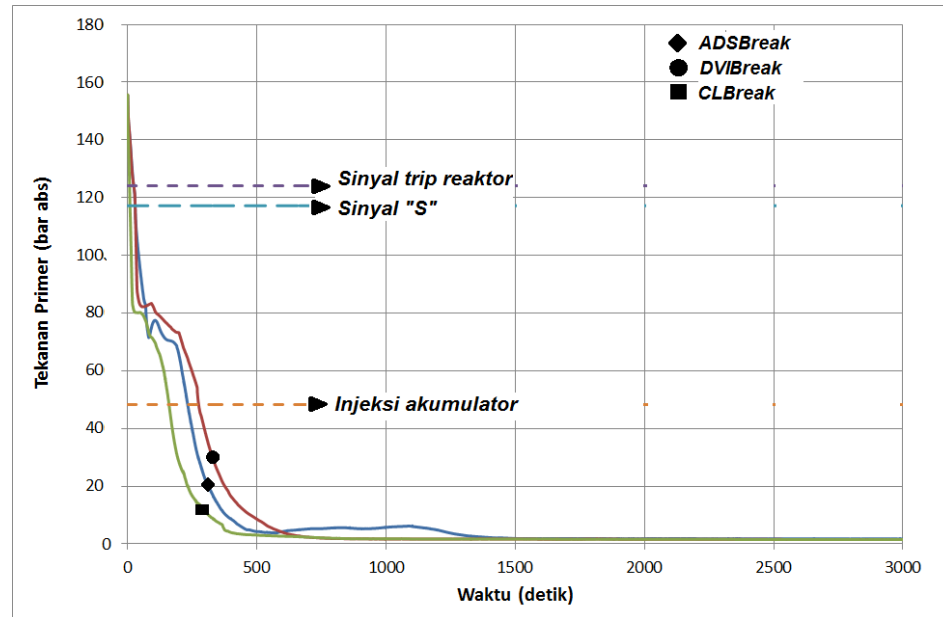

Gambar 5. Transien tekanan primer pada ADSBreak, DVIBreak, dan CLBreak

Perbedaan antara ketiga kejadian terjadi pada tercapainya sekuensi waktu untuk aktuasi PMS. Pada kejadian DVIBreak dan CLBreak, blowdown pendingin menyebabkan penurunan tekanan primer hingga tercapainya setpoint trip reaktor. Penurunan tekanan primer untuk CLBreak terlihat lebih tajam dibandingkan dengan DVIBreak dan ADSBreak karena luasan bocoran yang lebih besar. Penurunan daya reaktor akibat shutdown menyebabkan penurunan tekanan primer lebih lanjut hingga ke setpoint Safeguard ("S") untuk mengaktuasi fitur keselamatan pasif. Sinyal "S" akan memicu membukanya katup isolasi penukar kalor PRHR sehingga daya termal peluruhan teras dapat dibuang ke pendingin tangki IRWST secara sirkulasi alam. Sinyal "S" juga memicu 
membukanya katup isolasi tangki CMT sehingga terjadi aliran pendingin dari tangki CMT secara pasif yang disebabkan oleh perbedaan densitas antara lengan dingin dan outlet perpipaan DVI masuk ke bejana reaktor. Penurunan tekanan primer akibat blowdown pendingin juga akan mencapai ke tekanan katup isolasi akumulator hingga terjadi aliran pendingin dari akumulator melalui perpipaan DVI ke bejana reaktor. Aliran injeksi pendingin dari tangki CMT akan menyebabkan penurunan volume air borat yang dapat dilihat dari penurunan level air. Pada suatu saat, penurunan level air tangki CMT akan mencapai setpoint membukanya katup ADS tingkat 1 dan diikuti oleh membuka katup ADS tingkat 2, 3 dan 4 secara sekuensial yang menyebabkan penurunan tekanan primer lebih lanjut. Ketika tekanan primer berada di kisaran tekanan tangki IRWST, aliran injeksi pendingin dari tangki IRWST melalui perpipaan DVI ke bejana reaktor akan terjadi secara gravitasi. Pada kejadian ADSBreak, tidak terjadi kehilangan inventori pendingin primer ke luar sistem sungkup secara langsung, namun terjadi perpindahan massa pendingin primer ke pendingin tangki IRWST melalui membukanya katup ADS tingkat 1 . Kejadian tersebut memicu menurunnya tekanan primer hingga ke setpoint trip reaktor dan kemudian setpoint "S" untuk memicu aliran sirkulasi alam ke penukar kalor PRHR dan injeksi pendingin dari tangki CMT. Membukanya katup ADS tingkat 1 kemudian diikuti dengan membukanya katup ADS tingkat 2 dan 3. Sekuensi aliran pendingin melalui katup ADS tingkat 3 akan menurunkan tekanan primer hingga mencapai setpoint katup isolasi akumulator dan memulai injeksi pendingin akumulator. Ketika level air tangki CMT turun hingga $20 \%$, katup ADS tingkat 4 akan membuka dan menurunkan tekanan primer di kisaran tekanan tangki IRWST untuk memulai fase injeksi pendingin IRWST.

Sekuensi di atas akan berpengaruh pada proses pendinginan bahan bakar di teras yang disebabkan oleh berkurangnya inventori pendingin akibat kejadian small break LOCA. Salah satu parameter pendinginan teras adalah terbentuknya campuran air - uap pendingin di dalam bejana reaktor yang membentuk mixture level. Mixture level merupakan indikasi masih adanya proses pendinginan permukaan (kelongsong) bahan bakar melalui perpindahan kalor secara nucleate boiling [24]. Mixture level diukur dari bagian plenum bawah, melalui teras aktif hingga ke plenum atas dengan tinggi keseluruhan $8,46 \mathrm{~m}$, dimana tinggi teras aktif diukur dari plenum bawah adalah 6,26 meter. Gambar 6, 7, dan 8 menunjukkan mixture level yang terbentuk pada kejadian ADSBreak, DVIBreak, dan CLBreak, dimana mixture level terlihat masih di atas tinggi teras aktif.

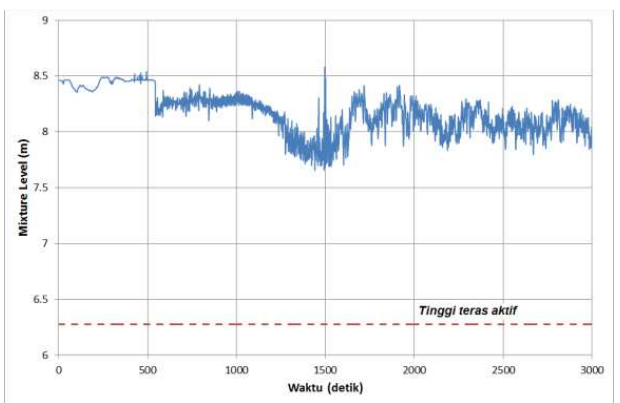

(a)

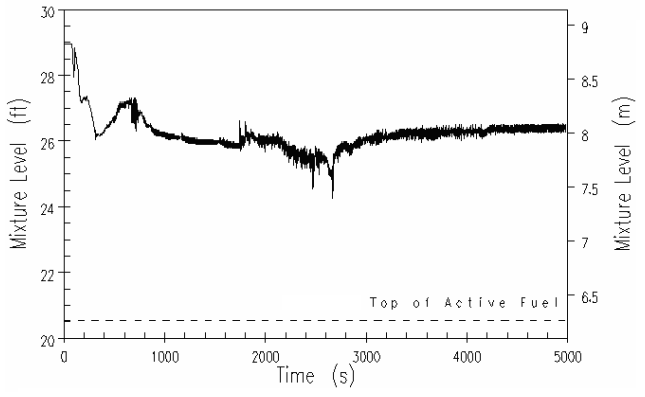

(b)

Gambar 6. Transien mixture level RELAP5 (a) dan NOTRUMP (b) untuk kejadian ADSBreak

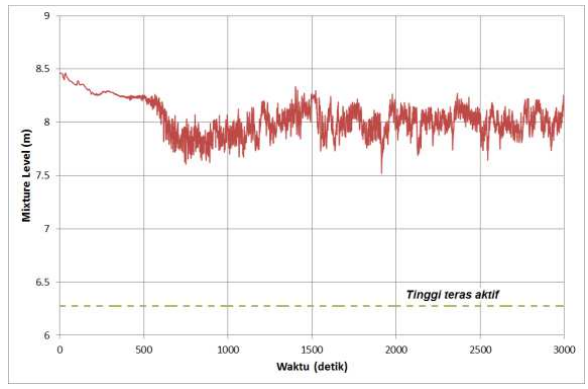

(a)

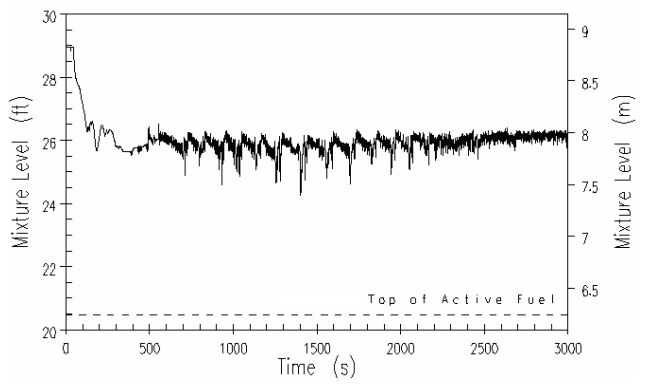

(b)

Gambar 7. Transien mixture level RELAP5 (a) dan NOTRUMP (b) untuk kejadian DVIBreak 


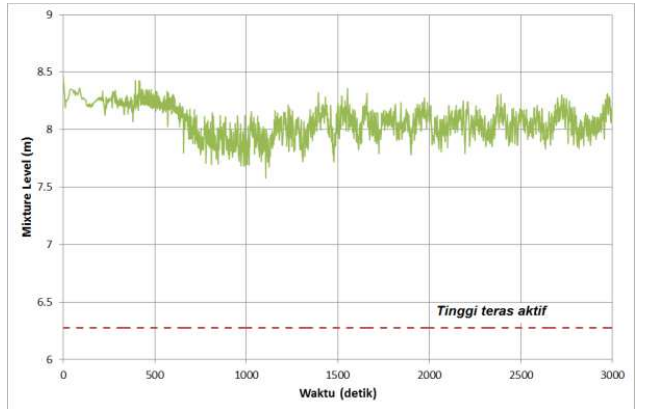

(a)

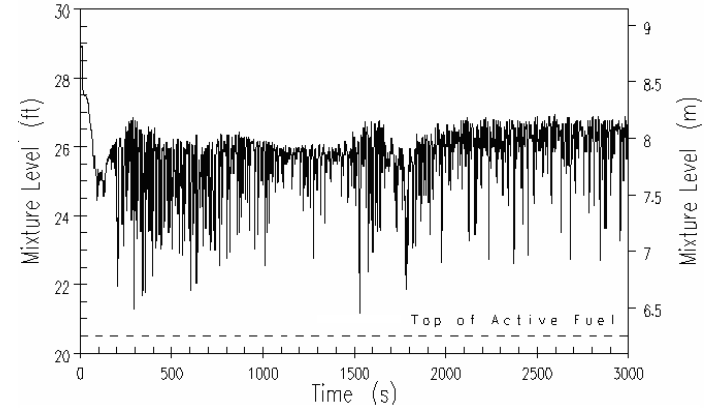

(b)

Gambar 8. Transien mixture level RELAP5 (a) dan NOTRUMP (b) untuk kejadian CLBreak

Mixture level terjadi akibat terbentuknya gelembung uap di dalam pendingin akibat pemanasan inventori pendingin yang telah berkurang oleh kalor peluruhan teras. Dari gambar-gambar di atas terlihat mixture level berada pada kisaran 8 meter atau di atas tinggi teras aktif. Mixture level juga menunjukkan seberapa jauh terjadi pengurangan inventori pendingin di dalam bejana akibat kebocoran. Perubahan mixture level juga dipengaruhi oleh penambahan pendingin primer melalui injeksi tangki CMT, akumulator, dan tangki IRWST. Hasil perhitungan mixture level dengan RELAP5 pada Gambar 6, 7, 8 di atas dibandingkan dengan hasil perhitungan dengan NOTRUMP untuk ketiga kejadian yang berbeda (Bab 15 referensi [7]). Pada tahap awal kejadian, hasil NOTRUMP menunjukkan penurunan yang lebih tajam bila dibandingkan dengan hasil RELAP5. Namun demikian, untuk kejadian ADSBreak dan DVIBreak, terlihat adanya kesamaan karakteristika mixture level di antara kedua program perhitungan hingga akhir perhitungan. Untuk kejadian CLBreak, walaupun secara rerata mixture level juga menunjukkan kesamaan nilai batas atas yaitu 8 meter, terlihat fluktuasi yang lebih dinamis pada hasil perhitungan NOTRUMP. Adanya fluktuasi tersebut kemungkinan berasal dari perbedaan pemodelan terutama pada bagian katup kebocoran walaupun memiliki luasan kebocoran yang sama. Faktor-faktor lain yang harus diprediksi adalah nilai loss coefficient, maupun subcooled dan two-phase discharge coefficient, dan perbedaan model teras serta downcomer di antara kedua program. Selain itu tidak ada data spesifik mengenai metode penghitungan mixture level pada perhitungan menggunakan NOTRUMP.

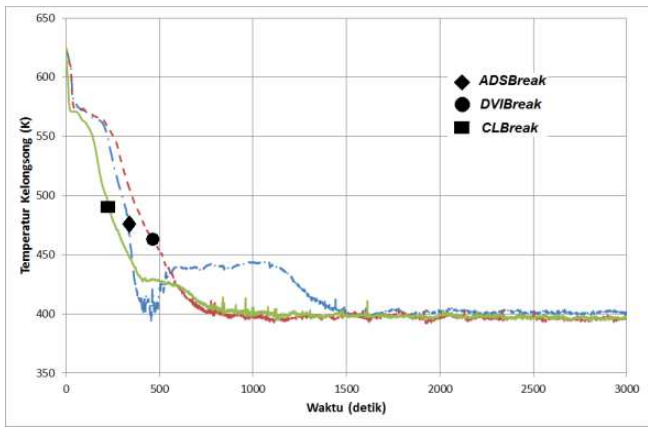

(a)

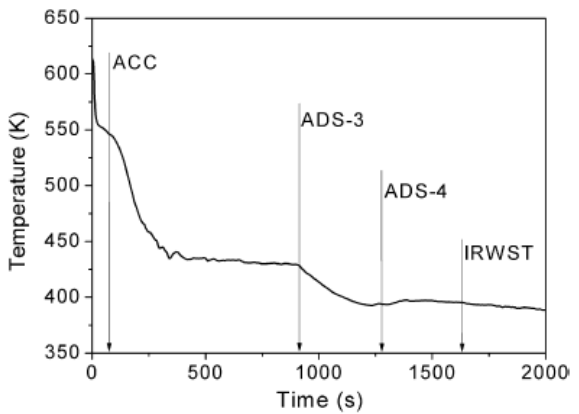

(b)

Gambar 9. Transien temperatur kelongsong untuk ADSBreak, DVIBreak, dan CLBreak, RELAP5 (a) dan CLBreak (b) [10]

Dampak campuran air-uap yang membentuk mixture level dapat dilihat pada transien temperatur kelongsong bahan bakar yang menunjukkan penurunan dari nilai operasi nominal $630 \mathrm{~K}$ $\left(357^{\circ} \mathrm{C}\right)$ seperti terlihat pada Gambar 9. Hingga akhir perhitungan, temperatur kelongsong menunjukkan kestabilan yang jauh di bawah kriteria keselamatan yaitu $1470 \mathrm{~K}$. Kestabilan temperatur kelongsong terjadi pada kisaran $400 \mathrm{~K}$ ketika pendinginan jangka panjang melalui injeksi dari IRWST telah terjadi. Pengukuran temperatur kelongsong pada Gambar 9 dilakukan pada posisi aksial teratas pada model bahan bakar yang terdiri dari 9 segmen dan menandai posisi 
tinggi teras aktif pada gambar hasil simulasi mixture level. Transien temperatur kelongsong tersebut juga tidak jauh berbeda dengan hasil eksperimen pada untai uji ROSA IV-LSTF [16] yang menunjukkan karakteristik transien temperatur kelongsong pada sistem keselamatan yang masih mengandalkan injeksi pendinginan secara aktif. Kemiripan hasil juga terlihat bila dibandingkan dengan program perhitungan RELAP5 dengan model AP1000 yang berbeda [10] untuk kejadian CLBreak dengan diameter 10 inchi. Dengan demikian keefektifan mixture level untuk mendinginkan bahan bakar dan menghindari core uncovery telah dapat ditunjukkan yang juga menunjukkan keefektifan fitur keselamatan pasif AP1000. Hasil simulasi juga menunjukkan bahwa model AP1000 yang telah dikembangkan menggunakan RELAP5 dapat digunakan untuk analisis keselamatan reaktor daya AP1000 dan hasilnya dapat dibandingkan dengan program perhitungan lain.

\section{KESIMPULAN}

Hasil simulasi untuk tiga kejadian small break LOCA pada reaktor daya AP1000 menggunakan program perhitungan RELAP5 menunjukkan bahwa mixture level untuk semua kejadian yang dianalisis berada di atas tinggi teras aktif yang menunjukkan tidak terjadinya core uncovery. Adanya mixture level berpengaruh pada transien temperatur kelongsong yang menurun dan menunjukkan pendinginan bahan bakar yang efektif. Keefektifan pendinginan teras juga disebabkan oleh berfungsinya injeksi pendingin melalui fitur keselamatan pasif menjadi ciri reaktor daya AP1000. Secara keseluruhan, hasil yang diperoleh menunjukkan model AP1000 yang telah dikembangkan dengan RELAP5 dapat digunakan untuk keperluan analisis kecelakaan dasar desain pada reaktor daya maju AP1000.

\section{DAFTAR PUSTAKA}

1. International Atomic Energy Agency. Fundamental Safety Principles. IAEA Safety Standards Series No. SF-1, Vienna 2006.

2. International Atomic Energy Agency. Assessment of Defence in Depth for Nuclear Power Plants. IAEA Safety Reports Series 46, Vienna 2005.

3. Commonwealth Edison Company. Updated Final Safety Analysis Report: Volume 6, Chapter 15: Safety Analyses", July 1993.

4. OECD Nuclear Energy Agency. Technology Roadmap Update for Generation IV Nuclear Energy Systems. Publication prepared by the Nuclear Energy Agency (NEA) of the Organisation for Economic Co-operation and Development (OECD), January 2014.

5. Nusret, A. Selected Examples of Natural Circulation for Small Break LOCA and Some Severe Accidents. IAEA Course on Natural Circulation in Water-Cooled Nuclear Power Plants. International Centre for Theoretical Physics (ICTP),Trieste, Italy, 2007.

6. Zhou, S, Zhang, X. Nuclear Energy Development in China: a Study of Opportunities and Challenges. Energy 2010; 35: 4282-4288.

7. Westinghouse Electric Co. AP-1000 European Design Control Document; 2009 Document Nr.: EPS-GW-GL-700 Revision 0.

8. Elshahat A, Abram T, Hohorst J, Allison, C. Simulation of the Westinghouse AP1000 Response to SBLOCA Using RELAP/SCDAPSIM. International Journal of Nuclear Energy Volume 2014.

9. Guozhi Z, Xinrong C, Xingwei S. Analysis of Fourth Stage of Automatic Depressurization System Failure to Open in AP1000 LOCA. Research Journal of Applied Sciences, Engineering and Technology 2014; 7: 18-22.

10. Yang J, Wang W.W, Qiu S.Z, Tian W.X, Su G.H, Wu Y.W. Simulation and Analysis on 10in. Cold Leg Small Break LOCA for AP1000. Annals of Nuclear Energy 2012; 46: 81 - 89.

11. Heng Xie, Shuangji He. The SCDAP/RELAP5 3.2 Model of AP1000 on SBLOCA. Progress in Nuclear Energy 2012; 61: 102-107. 
12. Wang W.W, Su G.H, Tian W.X, Qiu S.Z. Research on Thermal Hydraulic Behavior of Small-Break LOCAs in AP1000. Nuclear Engineering and Design 2013; 263: 380 - 394.

13. Andi Sofrany Ekariansyah, Surip Widodo, Susyadi, D.T. Sony Tjahjani, Hendro Tjahjono. Verifikasi Kecelakaan Hilangnya Aliran Air Umpan pada Reaktor Daya PWR Maju. Jurnal Teknologi Reaktor Nuklir Tri Dasa Mega 2012; 14: 76 - 90.

14. K.E. Carlson. PWR Small Break LOCA Evaluation Model, S-RELAP5 Based. Framatome ANP; 2001 Topical Report prepared by Siemens Power Corporation, EMF-2328 (P).

15. OECD Nuclear Energy Agency. Nuclear Fuel Behaviour in Loss-of-coolant Accident (LOCA) Conditions, State-of-the-art Report. Document issued by The NEA Working Group on Fuel Safety (WGFS), NEA No. 6846, 2009, ISBN 978-92-64-99091-3

16. Tasaka K, Kukita Y, Koizumi Y, Osakabe M, Nakamura H. The Results of $5 \%$ Small Break LOCA Tests and Natural Circulation Tests at the ROSA-IV LSTF. Nuclear Engineering and Design 1988; 108: $37-44$.

17. W.W.Wang, G.H. Su, S.Z. Qiu, W.X. Tian. Thermal Hydraulic Phenomena related to Small Break LOCAs in AP1000. Progress in Nuclear Energy 2011; 53: 407-419.

18. Schulz T.L. Westinghouse AP1000 Advanced Passive Plant. Nuclear Engineering Design 2006; 236: 1547 - 1557.

19. R.F. Wright. Simulated AP1000 Response to Design Basis Small-Break LOCA Events in APEX-1000 Test Facility. Nuclear Engineering and Technology 2007; 39: 287 - 298.

20. Andi Sofrany Ekariansyah, Surip Widodo, Susyadi, D.T. Sony Tjahjani, Hendro Tjahjono. Pengembangan Model untuk Simulasi Keselamatan Reaktor PWR 1000 MWe Generasi III+ menggunakan Program Komputer RELAP5. Jurnal Teknologi Reaktor Nuklir Tri Dasa Mega 2011; 13: 50 - 62.

21. Andi Sofrany Ekariansyah, Surip Widodo, Susyadi. Pemodelan Sistem Pendinginan Sungkup secara Pasif menggunakan RELAP5. Jurnal Teknologi Reaktor Nuklir Tri Dasa Mega 2012; 14: $137-145$.

22. Andi Sofrany Ekariansyah. Pemodelan Automatic Depressurization System (ADS) pada Reaktor Daya AP1000 untuk Simulasi Kecelakaan. Proseding Seminar Nasional Teknologi Energi Nuklir ke-14; 19 Juni 2014. Pontianak; 2014. p. 615 - 624

23. Andi Sofrany Ekariansyah, Julwan P. Purba, Surip Widodo, Sumantri H. Analisis Kecelakaan Hilangnya Pendingin Primer AP1000 Akibat Putusnya Pipa Direct Vessel Injection (DVI). Laporan Teknis Hasil Penelitian Tahun Anggaran 2014, Pusat Teknologi dan Keselamatan Reaktor Nuklir, 2014.

24. Christian Andersen. The Prediction of Two Phase Mixture Level and Cooling Conditions during a Partial Core Uncovery. Dissertation submitted for the degree of licentiate in mechanical engineering at Department of Nuclear Reactor Engineering, Royal Institute of Technology, Stockholm, Sweden, 1988. 